\title{
High-precision finishing hard steel surfaces using hydrostatic burnishing tool
}

\author{
S Swirad \\ Rzeszow University of Technology, The Faculty of Mechanical Engineering and Aeronautics, al. Powstancow Warszawy 12, 35-959 \\ Rzeszow, Poland
}

\begin{abstract}
The objective of this research aims to improve surface roughness of the hardened 145Cr6 (DIN) steel using the hydrostatic burnishing tool. The ball burnishing process with hydrostatic tools is very economical finishing process for various types of machine parts. This process reduces the height of surface unevenness, introduces compressive stresses at high depth (approx. $1 \mathrm{~mm}$ ) and increase the hardness of the surface layer. The flat surface optimal ball burnishing parameters have been determined after conducting the Taguchi L9 matrix experiment. The input parameters are speed, burnishing force and burnishing width. It also showed a positive effect of hydrostatics burnishing on roughness and geometric structure of the surface. In most cases, the result is anisotropic surface, reduced roughness, reduced amplitude values of parameters such as: $\mathrm{Sa}, \mathrm{Sz}$.
\end{abstract}

\section{Introduction}

Hard machining is usually defined as the process in which part pieces with hardness value over $45 \mathrm{HRC}$, but more typically in the range of 58-68 HRC are machining specially prepared tools. Hard machining is a specific process performed under unique thermo-mechanical and technological conditions were plastics deformation, heat generation and tool wear differ substantially from those observed in machining "soft" materials.

Burnishing is a cold working process in which plastic deformation occurs by applying pressure through a ball or roller on metallic surfaces. The principle of burnishing is shown on figure 1 . It is a finishing and strengthening process. Low surface roughness and good fatigue behaviours in some engineering components are becoming ever more demand. The burnishing process is an attractive finishing technique which can raise the strength of the surface of a workpiece as well as reduce its surface height [1-3].

Burnishing can be applied also to tempered steels after the turning operations, to reduce the helical pattern produces by the hard turning, applying burnishing in the opposite rotation sense to turning; therefore, helical paths cross in opposite directions braking the helices produced by turning $[4,5]$. Burnishing of hardened steel components is applied to materials over $45 \mathrm{HRC}$, usually as an operation after hard turning [6-8].

To improve the surface roughness, some researchers have been carried out recently into the optimal parameters of the ball burnishing process. Some dominant flat surface ball burnishing parameters for the hardened steel were burnishing force, burnishing speed and the feed $[9,10]$.
The improvement of the surface roughness through the burnishing process generally range $\mathrm{d}$ between $40 \%$ and $90 \%[11]$.

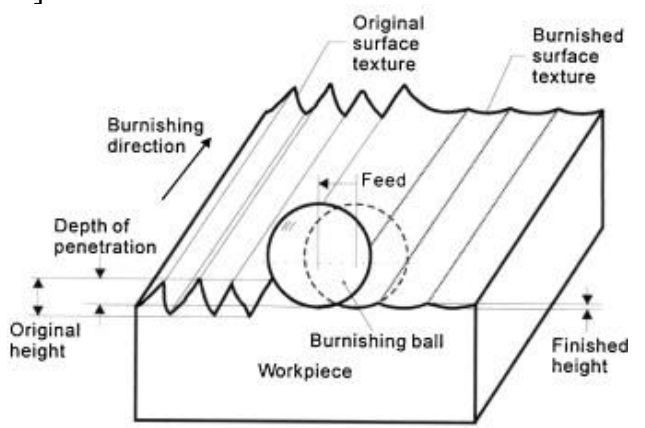

Figure 1. Ball burnishing principle [3].

\section{Experimental Investigation}

\subsection{Materials and experimental equipment}

Experimental investigation was carried out on flat bar of $145 \mathrm{Cr} 6$ steel. $145 \mathrm{Cr} 6$ is a medium cold work steel for oil hardening. The main application is small to medium size blanking and punching dies, shear blades, thread cutting tools, reamers. The hardness of this material is about 54 HRC after hardened and tempered heat treatment.

The burnishing tests were performed on Hass VF-1 vertical CNC machining centre. Initially, steel bars were grinded using, the general condition. The machined average roughness was found to be in the range $0.25 \mu \mathrm{m}$. The hydrostatic burnishing system used in this research consists of a high-pressure hydraulic pump (model 4.0 HGP) and the $6 \mathrm{~mm}$ diameter burnishing tool. The 
burnishing tool is based on a hydrostatics principle; the key element is a $6 \mathrm{~mm}$ ball made of ceramics [8].

\subsection{Taguchi method and design of experiment}

The Taguchi design is widely accepted and used in engineering analysis and optimization. Dr. Genichi Taguchi is regarded as the foremost proponent of robust parameter design, which is an engineering method for product or process design that focuses on minimizing variation and/or sensitivity to noise. In Taguchi methods, the number of experiments were reduced by orthogonal array and also reduce the effect of uncontrollable factors $[12,13]$. Taguchi proposed signal to noise $(\mathrm{S} / \mathrm{N})$ ratio as the objective function for orthogonal matrix experiments. Taguchi categorized the $\mathrm{S} / \mathrm{N}$ ratio into nominal the best type, larger the better type and smaller the better type based on the kind of objective function [14].

The $\mathrm{S} / \mathrm{N}$ ratio associated with the objective function for each trial of the orthogonal array is given by:

$$
\eta=-10 \times \log _{10}\left[(1 / n) \times \sum\left(y_{i}^{2}\right)\right]
$$

where $\mathrm{n}$ is the number of measurements in a trial/row and yi is the measured value in a run/row.

In this study, the smallest optimal value of surface roughness was selected for the $\mathrm{S} / \mathrm{N}$ ratio for better performances of factors $[15,16]$.

\subsection{Hard burnishing details}

In the current research, three control factors such as burnishing force, burnishing speed and burnishing width were considered based on author preliminary analysis. Each factor was examined at three levels to explore nonlinearity effects. The selected factors and their levels are presented in table 1. The experimental layout plan used for the present research is given in table 2 .

The surface roughness was measured to evaluate the quality of the burnished surface. The surface topographies were measured using Talysurf CCI Lite, which is a white light interferometer.

Table 1. Ball burnishing process parameters and their identified levels.

\begin{tabular}{ccccc}
\hline \multirow{2}{*}{ Code } & Control factor & \multicolumn{3}{c}{ Level } \\
\cline { 3 - 5 } & & 1 & 2 & 3 \\
\hline A & Burnishing force (P), [N] & 375 & 600 & 825 \\
B & Speed (v), [mm/min] & 500 & 1000 & 1500 \\
C & Width (a), [mm] & 0.02 & 0.04 & 0.06 \\
\hline
\end{tabular}

Table 2. Orthogonal array L9 with the experimental results for surface roughness $\mathrm{Sa}$.

\begin{tabular}{|c|c|c|c|}
\hline $\begin{array}{l}\text { Exp. } \\
\text { No. }\end{array}$ & $\begin{array}{l}\text { Coded } \\
\text { values }\end{array}$ & Actual values & $\begin{array}{cc}\text { Surface } & \text { Signal to } \\
\text { paramet } & \text { noise ratio } \\
\text { ers } & \mathrm{S} / \mathrm{N}\end{array}$ \\
\hline
\end{tabular}

\begin{tabular}{ccccccccc} 
& & & & $\mathrm{P}$ & $\mathrm{v}$ & $\mathrm{a}$ & $\mathrm{Sa}$ & $\mathrm{S} / \mathrm{N}$ \\
{$[\mathrm{mm} /$} & $\begin{array}{c}\mathrm{S} \\
\mathrm{min}]\end{array}$ & {$[\mathrm{mm}]$} & {$[\mathrm{m}]$} & $\mathrm{Sa}$ \\
\hline 1 & 1 & 1 & 1 & 375 & 500 & 0.02 & 0.10 & 20.26 \\
2 & 1 & 2 & 2 & 375 & 1000 & 0.04 & 0.14 & 17.03 \\
3 & 1 & 3 & 3 & 375 & 1500 & 0.06 & 0.18 & 15.06 \\
4 & 2 & 1 & 2 & 600 & 500 & 0.04 & 0.13 & 17.88 \\
5 & 2 & 2 & 3 & 600 & 1000 & 0.06 & 0.16 & 15.80 \\
6 & 2 & 3 & 1 & 600 & 1500 & 0.02 & 0.11 & 19.17 \\
7 & 3 & 1 & 3 & 825 & 500 & 0.06 & 0.15 & 16.41 \\
8 & 3 & 2 & 1 & 825 & 1000 & 0.02 & 0.12 & 18.41 \\
9 & 3 & 3 & 2 & 825 & 1500 & 0.04 & 0.13 & 17.56 \\
& Surface before burnishing & 0.25 & \\
\hline
\end{tabular}

\section{Results and discussion}

In the current study of burnishing process, the surface roughness is to be minimized. Thus "smaller is better" type category for surface roughness have been chosen. The subsequent $\mathrm{S} / \mathrm{N}$ ratios for each trial of $\mathrm{L} 9$ are summarized in table 2 . The analysis of means based and $\mathrm{S} / \mathrm{N}$ ratio was performed to decide the optimal levels of burnishing factors; the summary is presented in table 3 . The level of burnishing factors with the highest $\mathrm{S} / \mathrm{N}$ ratio is the optimal level. The best combination control factors settings is force - rank 3 , velocity - rank 2 and width rank 1 for minimum surface roughness.

Surface topography before burnishing and after burnishing are shown in figure 2 and 3 respectively. It can be seen from the analysis of the surface topographies that a ground surface has an anisotropic characteristic. The ordinate distribution is similar to a Gaussian

with low negative skewness. As a result of the ball burnishing, the height of the surface topography decreased. Depending on the machining conditions, the following amplitude parameters were obtained: $\mathrm{Sa}=0.1$ $0.18 \mu \mathrm{m}, \mathrm{Sz}=1.07-2.4 \mu \mathrm{m}, \mathrm{Sp}=0.62-1.2 \mu \mathrm{m}, \mathrm{Sv}=$ $0.8-1.2 \mu \mathrm{m}$; however, the lowest values for the amplitude parameter $\mathrm{Sa}=0.1 \mu \mathrm{m}$, correspond to lowest burnishing force $-375 \mathrm{~N}$, burnishing speed $-500 \mathrm{~mm} / \mathrm{min}$ and width $0.02 \mathrm{~mm}$.

Table 3. Response table for Signal to Noise Ratios and Response table for Means Main Effects.

\begin{tabular}{cccc}
\hline Level & Force [N] & $\begin{array}{c}\text { Velocity } \\
{[\mathrm{mm} / \mathrm{min}]}\end{array}$ & $\begin{array}{c}\text { Width } \\
{[\mathrm{mm}]}\end{array}$ \\
\hline 1 & 17.45 & 18.19 & 19.28 \\
2 & 17.62 & 17.09 & 17.49 \\
3 & 17.47 & 17.27 & 15.76 \\
Delta & 0.17 & 1.10 & 3.52
\end{tabular}




\begin{tabular}{cccc} 
Rank & 3 & 2 & 1 \\
\hline Level & Force $[\mathrm{N}]$ & $\begin{array}{c}\text { Velocity } \\
{[\mathrm{mm} / \mathrm{min}]}\end{array}$ & $\begin{array}{c}\text { Width } \\
{[\mathrm{mm}]}\end{array}$ \\
\hline 1 & 0.13 & 0.12 & 0.10 \\
2 & 0.13 & 0.14 & 0.13 \\
3 & 0.13 & 0.13 & 0.16 \\
Delta & 0.0049 & 0.0157 & 0.0542 \\
Rank & 3 & 2 & 1 \\
\hline
\end{tabular}
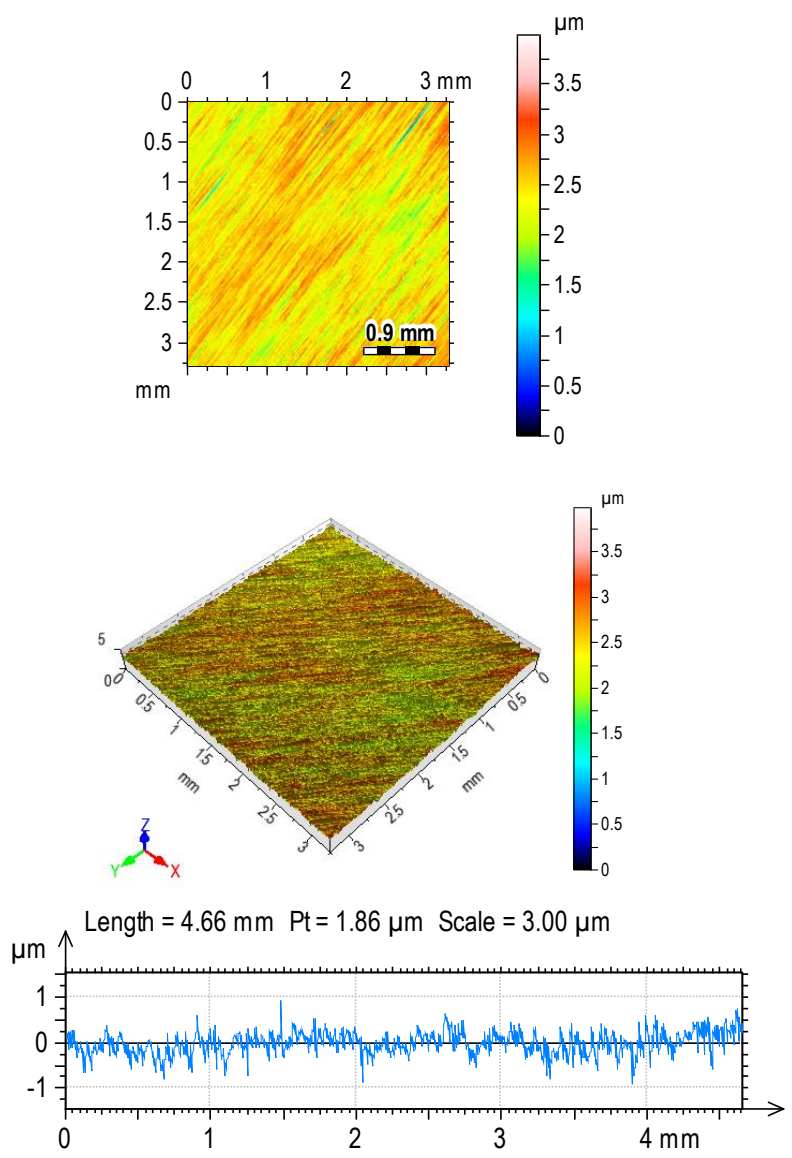

Figure 2. Topography and surface profile of the surface before burnishing.

From the main effect plot of surface roughness (figure 4), it is observed that when the burnishing force is increased from 375 to $600 \mathrm{~N}$ the surface roughness slightly decrease but surface roughness slightly increase from 600 to $825 \mathrm{~N}$. It was observed that the burnishing force has no strong effect on the process. Also, when burnishing width decrease the surface roughness rapidly decrease. At low burnishing width the plastic deformation is more intensive causing a greater decrease in surface roughness. At low value of burnishing width distance between the successive traces of the burnishing ball will be small, and also the ball will have more chances to smooth out the bulged edges of the previous traces as the ball passes slowly along the workpieces. This leads to a decrease in surface roughness. At small burnishing width, the ball is more deformed at the same place than at higher width. At higher burnishing width i.e. $0.06 \mathrm{~mm}$, the surface roughness drastically increases.
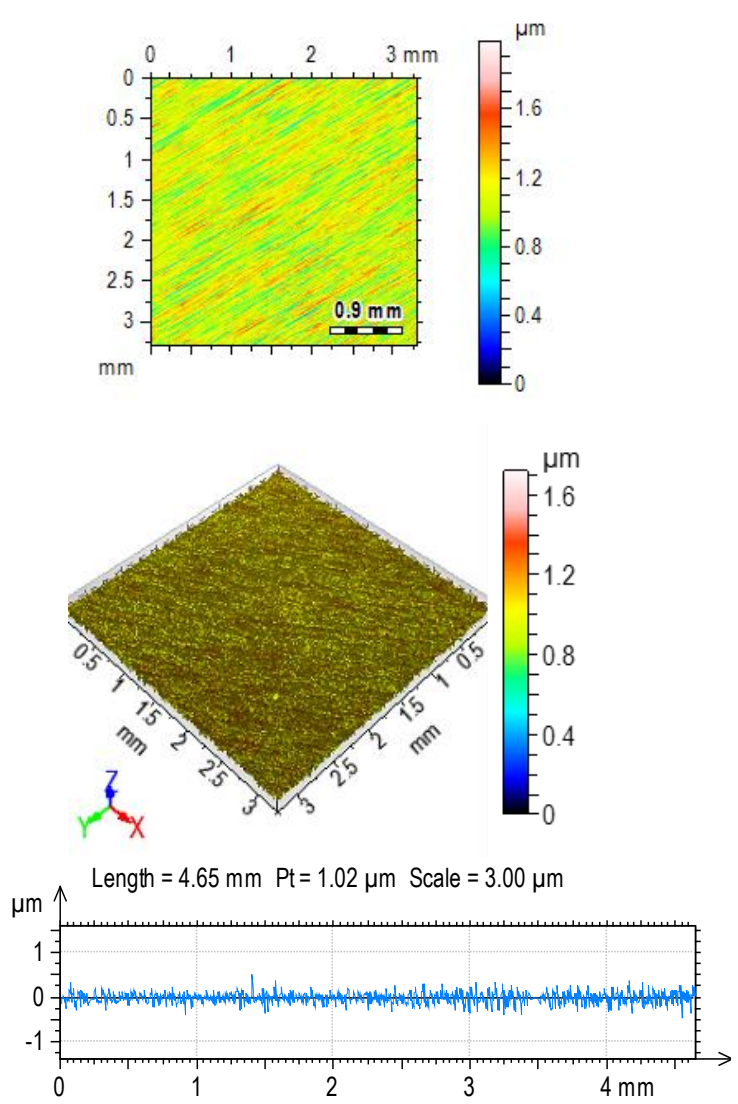

Figure 3. Topography and surface profile of the surface after burnishing, expt. no. 5 .

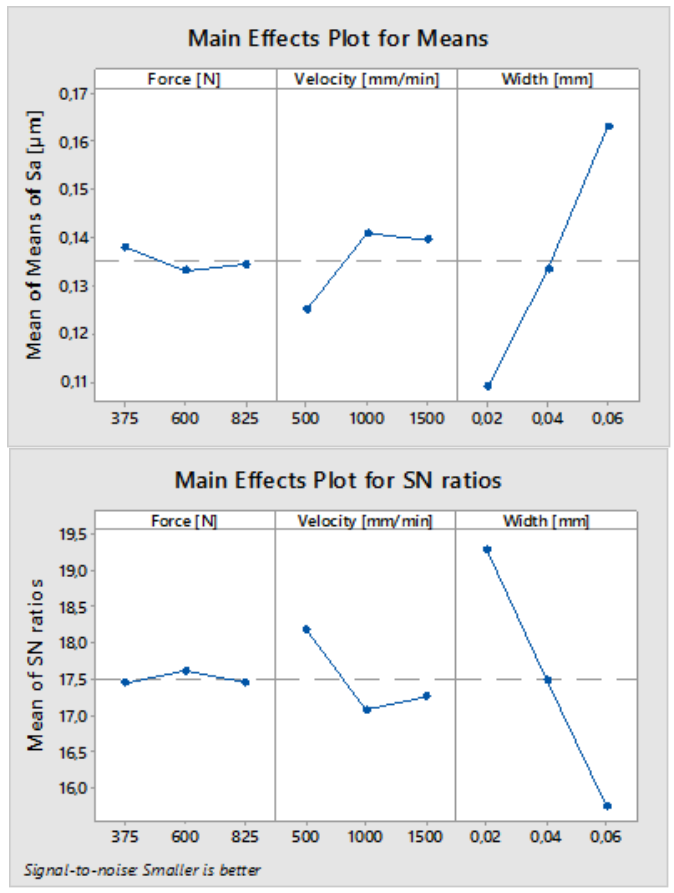

Figure 4. Main effect plot of surface roughness and Main effect plot for $\mathrm{S} / \mathrm{N}$ ratio. 
As the width is progressively increased, the distance between the successive burnishing tool traces increases, resulting in a reduction in likelihood for the burnishing tool to even out all the asperities of the former traces and therefore an enhanced surface roughness. Also at higher widths, the burnishing process produces larger feed marks with a center-line distance between two succeeding, indentations and hence raised surface roughness. Based upon of $\mathrm{S} / \mathrm{N}$ ratio the (figure 4) optimized ball burnishing process parameters accomplish a higher surface roughness are burnishing force $600 \mathrm{~N}$, velocity $1000 \mathrm{~mm} / \mathrm{min}$ and width $0.02 \mathrm{~mm}$.

\section{Conclusion}

In this paper, the effect of burnishing force, speed and width were studied on surface roughness. Taguchi method was used for optimization of these parameters to facilitate the optimization process. Conclusions from present research are given below:

- The optimal parameters combination for the minimum surface roughness was obtained by using the analysis of signal-to-noise ratio. The combination of parameters and their level for optimum surface roughness are force - rank 3, velocity - rank 2 and width - rank 1 .

- In general, the surface roughness increased with increased burnishing velocity. The effect of burnishing force was observed to be not significant for surface roughness. Also, the surface roughness decreased with decreased burnishing width.

- The best surface roughness value was obtain at burnishing force - $375 \mathrm{~N}$, burnishing speed at 500 $\mathrm{mm} / \mathrm{min}$ and burnishing width at $0.02 \mathrm{~mm}$.

Ball burnishing with hydrostatic tools can be efficiently used to machine hard steel components with hardness of $54 \mathrm{HRC}$, provided proper selection of machining parameters. In this process, we can effectively modify the roughness of the surface. Proper selection of process allows reduce geometrical structure of the surface (height parameters).

\section{References}

1. L. N. López de Lacalle, A. Lamikiz, J. A. Sánchez and J. L. Arana, The effect of ball burnishing on heat-treated steel and Inconel 718 milled surfaces. Int J Adv Manuf Technol (2007) 32: 958-968.

2. S. Fang-Jung, CH.Chuing-Hsiung, Precision surface finish of the mold steel PDS5 using an innovative ball burnishing tool embedded with a load cell. Precision Engineering 34 (2010) 76-84.

3. Fang-Jung Shiou, Chih-Cheng Hsu, Surface finishing of hardened and tempered stainless tool steel using sequential ball grinding, ball burnishing and ball polishing processes on a machining centre, Journal of Materials Processing Technology, Volume 205, Issues 1-3, 2008, Pages 249-258.
4. W. Bouzid, O. Tsoumarev, K. Sai, An investigation of surface roughness of burnished AISI 1042 steel. Int J Adv Manuf Technol (2004) 24: $120-125$.

5. M. Nemat, A. C. Lyons, An investigation of the surface topography of ball burnished mild steel and aluminium. Int $\mathrm{J}$ Adv Manuf Technol 16:469-473 (2000).

6. L. Luca, S. Neagu-Ventzel, I. Marinescu, Effects of working parameters on surface finish in ballburnishing of hardened steels. Precision Engineering 29 (2005) 253-256 2007.

7. Rodríguez, L.N. López de Lacalle, A. Celaya, A. Lamikiz, J. Albizuri, Surface improvement of shafts by the deep ball-burnishing technique. Surface \& Coatings Technology 206 (2012) 2817-2824.

8. Shepard, M.J., Prevey, P.S. and Jayaraman, N, 2003, "Effects of Surface Treatment on Fretting Fatigue Perfomance of Ti-6Al-4V," Proceedings of the 8th National Turbine Engine High Cycle Fatigue (HCF) Conference, April 14-16, Monterey, CA.

9. L.N. López de Lacalle, A. Lamikiz, J. Muñoa, J.A. Sánchez, Quality improvement of ball-end milled sculptured surfaces by ball burnishing. International Journal of Machine Tools \& Manufacture 45 (2005) 1659-1668.

10. S. Swirad - Surface texture characterization of alpha-beta titanium alloy (Ti6-A14-V) after hydrostatic burnishing, MATEC Web of Conferences 189, 01001 (2018), MEAMT 2018

11. Rodríguez, L.N. López de Lacalle, A. Celaya, A. Lamikiz, J. Albizuri, Surface improvement of shafts by the deep ball-burnishing technique. Surface \& Coatings Technology 206 (2012) 2817-2824.

12. Goutam D. Revankar, Raviraj Shetty, Shrikantha S. Rao, Vinayak N. Gaitonde, Analysis of surface roughness and hardness in ball burnishing of titanium alloy, Measurement, Volume 58, 2014, 256-268.

13. Turgay Kivak, Optimization of surface roughness and flank wear using the Taguchi method in milling of Hadfield steel with PVD and CVD coated inserts, Measurement, Volume 50, 2014, Pages 19-28

14. İlhan Asiltürk, Harun Akkuş, Determining the Effect of Cutting Parameters on Surface Roughness in Hard Turning Using the Taguchi Method, Measurement 44(9):1697-1704, (2011)

15. Manivel, D., and R. Gandhinathan. Optimization of surface roughness and tool wear in hard turning of austempered ductile iron (grade 3) using Taguchi method. Measurement 93 ,108116, (2016)

16. S. Krishna Madhavi, D. Sreeramulu, M. Venkatesh, Evaluation of Optimum Turning Process of Process Parameters Using DOE and PCA Taguchi Method, Materials Today: Proceedings, Volume 4, Issue 2, Part A,2017, Pages 1937-1946, 